\title{
A Review on Different ANN Based Fault Detection Techniques for HVDC Systems
}

\author{
Khushboo Nagar \\ M.Tech Scholar \\ Department of Electrical Engineering \\ VITS Indore India
}

\author{
Manish Shah MIEEE, MIE, MISLE \\ Assistant Professor \\ Department of Electrical Engineering \\ VITS Indore India
}

\begin{abstract}
Neural Network has been one among few best choices for the detection of faults in electrical systems. HVDC transmission system has no doubt first choice for the long transmission of electricity all over the world. This paper presents a use of different artificial neural network for the fault detection \& classification in HVDC transmission system. Here an attempt is made to cite the scholarly work done and available on renounced journals with excellent review on their work. The work is valuable and may be light house for beginners in the same field.
\end{abstract}

\section{Keywords}

Artificial Neural Network, Wavelet Transform, Faults, HVDC System, Travelling Waves

\section{INTRODUCTION}

An HVDC Transmission has very efficient means of transferring power in bulk over long distances due to rapid technical advancement in power electronics [34]. For the stable \& reliable operation of HVDC system, the fault classification \& location \& clearance of fault in the HVDC lines are very important. Fault classification and location of HVDC transmission system is currently afford by the function of repeater stations [12]. Reliable operation of HVDC transmission system depends on fast detection and clearing the fault [7]. An Artificial Neural Network (ANN) has been used for fault detection in HVDC system. Only four types of faults including, short circuit in DC transmission system, single line to ground (SLG), double line to ground (DLG) \& three phase fault in AC system has been detected[7]. Artificial Neural Networks (ANNs) is a mathematical model inspired by biological neural networks [15]. ANNs have been. Artificial Neural Networks (ANNs) are powerful in pattern recognition and classification. They possess excellent features such as generalization capability, noise immunity, robustness \& fault tolerance [23]. ANN based techniques have been used in power system protection \& encouraging results are obtained [23]. This paper aims to investigate pattern of the over current due to different cases, for instance, fault \& load change. The fault taking place on HVDC transmission lines may cause instability of power system \& therefore a large economic loss. Travelling wave based methods are widely used for the detection of faults in HVDC system. But it has disadvantage such as it is easily affected by noise, difficulty in accurate detection of wave head, requirement of complex \& expensive equipment, vulnerable to interference of external signals etc. [b]. With the rapid advance of microelectronics technology and microcomputer protection, travelling wave theory has been implemented and adopted in HVDC transmission line successfully [24]. Neural Network $(\mathrm{NN})$ gives the best results in fault detection and classification [b]. Travelling wave, which is a kind of nonstationary signal with mutation, spread along the line when HVDC transmission line fault happens [12]. The objective of this paper is to propose an HVDC transmission line fault localization algorithm based on radial basis function neural network with wavelet packet decomposition. The effectiveness of wavelet transform [WT] in identifying \& locating the fault has been discussed [2]. In this paper an ANN based approach is used \& an accurate fault classifier and locator algorithm is designed.

\section{ARTIFICIAL NEURAL NETWORK (ANN)}

ANNs are non linear information (signal) processing devices, which are built from interconnected elementary processing devices are called neurons. The arrangement of neurons into layers \& the pattern of connection within \& in-between layer are generally called as the architecture of the net. [35]. ANNs have been used for the protection of power transmission lines. The excellent pattern recognition and classification abilities of neural networks have been cleverly utilized to address the issue of transmission line fault location.

Artificial neural network (ANN) can be applied to fault detection and classification effectively because it is a programming technique, capable to solve the non linear problems easily [3]. They are widely accepted and used in the problem of fault detection and fault classification because of the following features:

- The ANN output is very fast, reliable and accurate depending on the training, because its working depends upon a series of very simple operations.

- The conditions of the electrical power system change after each and every disturbance. Hence a neural network is capable to incorporate the dynamic changes in the power systems.

The values of the pre fault and post fault voltage and current of respective three phases are very different and are governed by the type of fault. Thus, the fault classification method required a neural network that allows it to determine the type of fault from the patterns of pre fault and post fault voltages and currents, which are generated from the values measured from a three phase transmission 
line of an electrical power system at one terminal. The neural network is based upon the total six numbers of inputs, i.e. the voltages and currents of respective three phases. The neural network is trained by using these six inputs. The total number of outputs of the neural network is four in numbers, i.e. three phases A, B, C and fourth is ground of three phase transmission line.

\section{TRAVELLING WAVE PHENOMENON}

Travelling wave fault location methods are usually more suitable for application to long lines. Travelling wave methods for transmission lines fault location have been reported since a long time. It is well known that when a fault occurs in overhead transmission lines systems, the abrupt changes in voltage and current takes place, at the point of the fault. When a fault occurs on the HVDC line, according to travelling wave theory, voltage and current travelling waves transmits on the line. During the occurrence of a fault, travelling waves carry the information about the fault which can be used for fault detection and line protection [38]. If the times of arrival of the travelling waves in the two ends of the transmission line can be measured precisely, the fault location then can be determined by comparing the difference between these two arrival times of the first consecutive peaks of the travelling wave signal. Travelling-wave-based line fault location principle has been successfully applied to transmission line fault location in the conventional HVDC systems with two terminals [37].

\section{WAVELET TRANSFORM}

A wavelet is a waveform of effectively limited duration that has an average value of zero [37]. Wavelet transform has received greater attention in fault analysis due to its ability in analyzing the travelling waves than conventional methods of analysis. The method using wavelet transforms for detecting a HVDC Transmission line faults is proposed after simulating the HVDC system for various faults. The simulation results show that the application of wavelet technique leads to a more reliable solution for recognition of faults and provides a good basis for the new protection scheme for the HVDC lines.

\section{CONVERTER FAULTS IN HVDC SYSTEM}

HVDC system considered for analysis is shown in Figure 1 which consists of rectifier at sending end and inverter at receiving end. Converters are connected with a DC transmission line represented by a resistance and DC inductor on either side of the line [32].

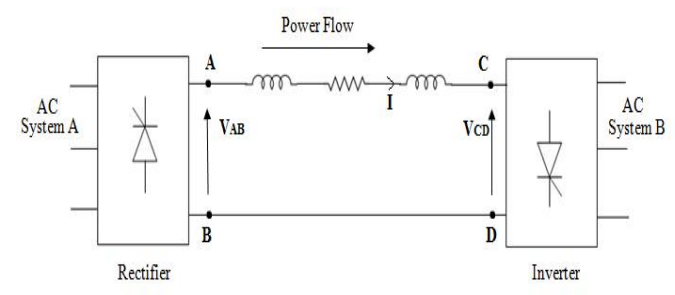

Figure 1 HVDC system model

The common malfunctions reported for the HVDC thyristor converters are:
i. Backfire: It is conduction in the reverse direction.
ii. Fire-through: It is conduction during blocking.
iii. Misfire: It is failing of conduction in spite of the positive gate and anode to
cathode voltages.
iv. Commutation Failure

\section{FAULT CLASSIFICATION}

Fault Detection is also followed here in terms of the design $\&$ development of the classifier neural network. The designed network takes in the sets of six inputs (the three phase voltages and currents values normalized with respect to their corresponding pre-fault values) [3]. The neural network has four outputs, each of them corresponding to the fault condition of each of the three phases \& one output for the ground line. Hence output are either 0 or 1 denoting the absence or presence of a fault on the corresponding line (A, B, C or G where A, B, C denote the respective 3 phases of the transmission line system \& $\mathrm{G}$ denotes the ground). The proposed neural network should be capable to accurately distinguish between the ten possible categories of faults [3].

In HVDC, external fault is either at the rectifier stations or at the inverter stations. The external fault identified by using the value of current. The nominal value of terminal currents is 1 per unit (pu). Whenever fault occurs, this value changes. If the values of terminal currents are greater than the nominal value, fault will be at inverter side. If the value of those currents is less than the nominal value, fault will be at rectifier side [36].

The faults that occur in an HVDC line are mainly of two types. These faults can be identified easily by analyzing the current data. Current at the two terminals A \& B of the DC transmission line are different in each type of fault [36]. There are two types of fault.

1. Open Circuit Fault: In this fault the line breaks and an open circuit fault occurs. Both terminal currents are zero.

2. Pole to Ground Fault: In this fault the values of terminal currents are not equal to zero. The value of terminal current $\mathrm{I}_{\mathrm{A}}$ will be greater than $\mathrm{I}_{\mathrm{B}}$. 


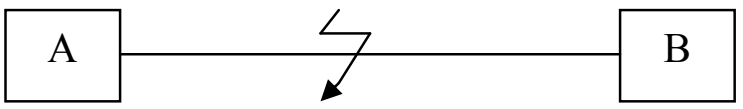

Figure 2 pole to ground fault

\section{HVDC FAULT DETECTION}

In this paper, wavelet transform is used for detection of faults and artificial neural network is used for classification of faults. The neural network is provided with six inputs during the fault detection process. The inputs are three voltages of respective three phases and three currents of the respective three phases. The value of input voltages and input currents are normalized with respect to the pre-fault values of the voltages and currents respectively. The output of the neural network is in simple yes or no form, i.e. 1 or 0 , which indicates whether the fault has been occurred or not [3].

The 12 pulse HVDC system model is studied for various faults like (a) DC line short circuit, (b) short circuit on the $\mathrm{AC}$ side of inverter station and (c) normal operation as reference case. The short circuit faults on the $\mathrm{AC}$ side of the inverter are Single Line to Ground fault (LG fault), Line to Line fault (LL fault), Triple line (symmetrical) fault on the AC side of the inverter (LLL fault). It is not easy to identify the faults and to make correct protection decision within $3-5 \mathrm{~ms}$ by using traditional methods, as the fault generated travelling waves, will be similar in nature. It is even more difficult if there is noise [38]. If the converter fault is considered then Fault detection of HVDC converter is based on the fact that every operation of the converter valve is associated with a set of conduction pattern of the valves. Fault detection is basically treated as a problem of pattern recognition and neural networks are extensively used where pattern recognition is needed. Therefore, by integrating the neural network algorithm with HVDC system model the faults in converter can be detected [33]. The faults such as valve short circuit, misfire and arc through faults are discussed in this paper. With the help of ANN and wavelet transformation, the fault is easily classified and detected respectively. Wavelet analysis expands functions not in terms of trigonometric polynomials but in terms of wavelets, which are generated in the form of translations and dilations of a fixed function called the mother wavelet. Compared with Fourier transform, wavelet can obtain both time and frequency information of signal, while only frequency information can be obtained by Fourier transform. Each wavelet is created by scaling and translation operations in a special function called mother wavelet. A mother wavelet is a function that oscillates, has finite energy and zero mean value [32]. When fault occurs on a DC line, the travelling waves propagate along the line and are reflected at discontinuous points of surge impedance. This leads to an abrupt change in the voltage and current and hence in the reverse voltage travelling wave. The sudden changes are the edges in signal processing. The wavelet theory is used to detect the sudden changes, and the fault location can be identified along with the recognition of the fault by obtaining the time delay $\Delta t$ in seconds between the two absolute maximum values of the wavelet coefficients. By denoting

$$
L=\frac{v \times \Delta t}{2}
$$

Where,

$v$ is the velocity of travelling wave in $\mathrm{km} / \mathrm{s}$ and

$\mathrm{L}$ is the fault distance in $\mathrm{km}$ from the measuring point

The time delay between the first two maximum wavelet coefficients of the reverse voltage travelling wave is $\Delta t=$ 0.00102 seconds, thus the fault location from the measuring terminal can be calculated and is equal to $151 \mathrm{~km}$. One of the fault commutation failures can be identified clearly from the HVDC line fault with the polarity change of wavelet coefficient.

\section{CONCLUSION}

Here an attempt is made to gather the collection and review the work done on same and allied areas by scholars. The conclusion might be the ANN and similar techniques are capable to detect analysis and classify the different faults in HVDC systems and accessories.

\section{REFERENCES}

[1] V. sulochana, A. Francis, Dr. Andrew Tickle, "Morphology Based Radon Processed Neural network for Transmission Line Fault Detection", International Conference on Advances in Computing, Communications and Informatics (ICACCI) IEEE, pp. 1137-1143, 2015.

[2] Y.M. Yeap, A. UKIL, "Wavelet Based Fault Analysis in HVDC System" Annual Conference of the IEEE Industrial Electronics Society IEEE, pp. 2472-2478, 2014.

[3] M. Jamil, S. Kumar Sharma \& R. Singh, "Fault detection and classification in electrical power transmission system using artificial neural network" SpringerPlus, pp. 113, 2015.

[4] I. Baqui, I. Zamora, J. Mazon, G. Buigues, "High impedance fault detection methodology using wavelet transform and artificial neural networks" Elsevier, pp. 1325-1333, 2011.

[5] M Ramesh, A. Jaya Laxmi, "Fault Identification in HVDC using Artificial Intelligence - Recent Trends and Perspective" IEEE, pp. 1-6, 2012.

[6] K. G. Narendra, V. K. Sood, K. Khorasani, R. Patel, "Application of a Radial Basis Function (RBF) Neural Network for Fault Diagnosis in a HVDC System" IEEE, pp. 177-183, 1998.

[7] J. Moshtagh, M. Jannati, H. R. Baghaee and E. Nasr, "A Novel Approach for Online Fault Detection in HVDC Converters" IEEE, pp. 307-311, 2008.

[8] L L Lai, F Ndeh-Che, Tejedo Chari, "Fault Identification In HVDC Systems With Neural Networks", IEE 2nd International Conference on Advances in Power System Control, Operation and Management, December 1993, Hang Kong, pp. 231-236.

[9] M.Khodaparastan, ,A.S.Mobarake, G.B.Gharehpetian, S.H Fathi, "Smart Fault Classification in HVDC System Based on Optimal Probabilistic Neural Networks", pp. 1-4. 
[10] H. Kanoh, K. Kanemaru, M. Kaneta, M. Nishiura, “A Study on Practical Fault Location System for Power Transmission Lines using Neural Networks", pp. 9-13.

[11] H. Etemadi, V.K. Sood, K. Khorasani, R. V. Patel, "Neural Network Based Fault Diagnosis in an HVDC System", International Conference on Electric Utility Deregulation and Restructuring and Power Technologies, 2000, pp. 206-214.

[12] Hang Cui, Niannian Tu, "HVDC Transmission Line Fault Localization Base on RBF Neural Network with Wavelet Packet Decomposition", IEEE International Conference on Service Systems and Service Management (ICSSSM), 2015, pp. 1-4

[13] K.S.SuaruP, H.S.Chandrasekharalah, "Fault detection and Diagnosis of Power Converters using Artificial Neural Network", IEEE International Conference on Power Electronics, Drives and Energy Systems for Industrial Growth, 1996, pp. 1054-1058.

[14] P.Sanjeevikumar, B. Paily, M. Basu, M. Conlon, "Classification of Fault Analysis of HVDC Systems using Artificial Neural Network", IEEE Power Engineering Conference (UPEC), 2014, pp. 1-5.

[15] Preeti Gupta, R. N. Mahanty, "Artificial Neural Network based Fault Classifier and Locator for Transmission Line Protection", IOSR-JEEE, Vol. 11, Issue 1 Ver. I (Jan - Feb. 2016), PP 41-53.

[16] S. A. M. Javadian, M.-R. Haghifam, N. Rezaei, "A Fault Location and Protection Scheme for Distribution Systems in presence of DG Using MLP Neural Networks", Power \& Energy Society General Meeting, 2009, IEEE, pp. 1-8.

[17] S.A.M. Javadian, A.M. Nasrabadi, M.R. Haghifam, J. Rezvantalab, "Determining Fault's Type and Accurate Location in Distribution Systems with DG Using MLP Neural Networks", IEEE International Conference on Clean Electrical Power, 2009 pp. 284-289.

[18] Xiangning Lin, Peng Mao , Hanli Weng, Bin Wang, Z Q Bo and A Klimek, "Study on Fault Location for High Voltage Overhead Transmission Lines Based on Neural Network System", IEEE, International Conference on Intelligent Systems Applications to Power Systems, 2007, pp. 1-5.

[19] D.S. Gastaldello, A.N. Souza, C.C.O. Ramos, P. da Costa Junior and M.G. Zago, "Fault Location in Underground Systems Using Artificial Neural Networks and PSCAD/EMTDC", IEEE 16th International Conference on Intelligent Engineering Systems, June 1315, 2012, pp. 423-427.

[20] F. Dehghani, H. Nezami, "A New Fault Location Technique on Radial Distribution Systems Using

Artificial Neural Network", 22nd International Conference on Electricity Distribution, CIRED2013, pp. 1-4.

[21] P. Bunnoon, "Fault Detection Approaches to Power System: State-of-the-Art Article Reviews for Searching a New Approach in the Future", International Journal of Electrical and Computer Engineering (IJECE) Vol. 3, No. 4, August 2013, pp. 553 560.

[22] Kaiping Yu, Fang Yang, Hong Guo, Jinquan Xu, "Fault Diagnosis and Location of Brushless DC Motor System Based on Wavelet Transform and Artificial Neural Network", International Conference on, Electrical Machines and Systems (ICEMS), 2010, pp. 1-5.
[23] H. Khorashadi-Zadeh, M. R. Aghaebrahimi, “A Novel Approach to Fault Classification and

Fault Location for Medium Voltage Cables Based on Artificial Neural Network", World Academy of Science, Engineering and Technology, 2008, pp. 1100-1103.

[24] Mr. Shrishail H. Patale, Prof. M. S. Potdar, "A Review on HVDC Transmission Line Protection with Different Techniques" International Journal of Engineering Sciences \& Research Technology, ISSN: 2277-9655, pp. 820-824.

[25] L. L. Lal, F Wdeh-Che, Tejedo Chari, "HVDC Systems Fault Diagnosis with Neural Networks", 1993 The European Power Electronics Association, pp. 145-150.

[26] H. Livani, C. Y. Evrenosoglu, "A single-ended fault location method for segmented HVDC transmission line", 2013 Elsevier, Electric Power Systems Research 107 (2014) 190- 198.

[27] N. P. Srivastava, R. K. Srivastava, P. K. Vashishtha, "Fault Detection and Isolation (FDI) Via Neural Networks", ISSN : 2248-9622, Vol. 4, Issue 1( Ver.1), January 2014, pp.81-86.

[28] S. LeBlond, R.BerthoJr., D.V.Coury, J.C.M.Vieira, "Design of protection schemes for multi-terminal HVDC systems" Elsevier 2015, pp. 966-973.

[29] Zhiqing Yao, Qun Zhang, Peng Chen, Qian Zhao, "Research on fault diagnosis for MMC-HVDC

Systems", Springer, pp. 1-7.

[30] A. Abu-Jasser, M. Ashour, "A Backpropagation Feedforward NN for Fault Detection and Classifying of Overhead Bipolar HVDC TL Using DC Measurements",

Journal of Engineering Research and Technology, Vol. 2, Issue 3, September 2015, pp. 197-202.

[31] S. Tom, J. Thomas, Ganesh M, "A Novel Algorithm for Fault Location and Identification in HVDC Transmission Lines Based on Transients", IEEE International Conference on Emerging Research in Electronics, Computer Science and Technology - 2015, pp. 224-229.

[32] C. Venkatesh, P. Venugopal Rao, "Wavelet-ANN based Classification of HVDC Converter Faults", International Conference on Power Systems (ICPS), 2016 IEEE, pp. 1-5.

[33] M. S. Shastrakar, M. B. Gaikwad, "Application of Artificial Neural Network In Fault Detection of HVDC Converter", International Journal of Engineering Research \& Technology (IJERT) Vol. 2 Issue 5, May - 2013 ISSN: 2278-0181.

[34] A. Swetha, P. Krishna Murthy, N. Sujatha and Y. Kiran, "A Novel Technique for the Location of Fault on A HVDC Transmission Line", ARPN Journal of Engineering and Applied Sciences VOL. 6, NO. 11, NOV. 2011 ISSN 1819-6608, pp. 62-67.

[35] S. N. Sivanandam, S. Sumathi, S. N. Deepa, "Introduction to Neural Networks using MATLAB 6.0.", The McGraw- Hill Companies.

[36] Sherin Tom, Jaimol Thomas, "A New Fault Identification Method for HVDC Transmission Line", International Journal of Science and Research (IJSR) Volume 4 Issue 11, November 2015, ISSN (Online): 23197064, pp. 729-734.

[37] S. M. Mangalge, S. D. Jawale, "A Review on Fault Location Techniques in Long HVDC Transmission Lines", International Journal of Advanced Research in Electrical, Electronics and Instrumentation Engineering, Vol. 5, Issue 5, May 2016, pp. 4220-4226. 
[38] Pannala Krishna Murthy, J.Amarnath, S. Kamakshiah, B.P. Singh, "Wavelet Transform Approach for Detection and Location of Faults in HVDC System", Third international Conference on Industrial and Information Systems, 2008. ICIIS 2008, IEEE, pp. 1-6.

[39] L. wen-li, S. li-qun, "The Review of High Voltage DC Transmission Lines Fault Location”,International Journal of Computer, Consumer and Control (IJ3C), Vol. 3, No.4 (2014), pp. 21-28.

[40]

Sourabh Mehto, Rahul Agarwal, Manish Shah, "A Comparative Study Based on PI and Fuzzy Control of Inverter fed Induction Motor Drive", International Journal of Research (IJR) Vol-2, Issue-2 February 2015 ISSN 2348-6848, pp.75-79.

[41] Juhi Nagpal, Rahul Agarwal \& Manish Shah, "A Comparative Study on Different Speed Control Methods of D.C. Drives for Electric Vehicle", International Journal of Research (IJR) e-ISSN: 2348-6848, p- ISSN: 2348-795X

Volume 2, Issue 07, July 2015, pp. 1-6.

[42]

Khushboo Hardia, Neha Maithil \& Manish Shah, "Particle Swarm Optimization Applied To Economic Load Dispatch Problem", International Journal of Research (IJR) e-ISSN: 2348-6848, p- ISSN: 2348-795X Volume 2, Issue 09, September 2015, pp. 834-843.
[43] Jyoti verma, Manish Shah, "Simulation and Analysis of H-bridge Cascade Multi level Inverter Fed Induction Motor Drive for Industrial Applications", International Journal of Innovative Research In Electrical, Electronics, Instrumentation And Control Engineering Vol. 4, Issue 3, March 2016, pp. 17-19.

[44] Manish Shah, Rahul Agrawal, "A Review On Classical And Modern Techniques with Decision Making Tools For Load Forecasting", International Journal of Emerging Trends in Engineering and Development Issue 3, Vol.6 (November 2013), pp. 174-184.

[45] Ritu Bhateja, Manish Shah, "A Proposed Method for Smooth Speed Control of Indirect Vector Control InverterFed Induction Motor Drive using Boost Converter Topology",

International Journal of Emerging Trends in Engineering and Development Issue 6, Vol. 5 (September 2016), pp. 110.

[46] Sudeep Mohaney, Sourabh Mehto, Manish Shah, "Modeling and Optimization of Elevator Group Control System for High Rise Commercial Building", IEEE International Conference on Computer, Communication and Control (IC4-2015).

[47] Sudeep Mohaney, Manish Shah, "Emerging Trends in Vertical Elevating System", International Journal of Engineering and Management Research Vol.-5, Issue-1, February-2015, pp. 51-56. 